ISSN 0258-7122

Bangladesh J. Agril. Res. 40(1): 153-161, March 2015

\title{
CORRELATION AND PATH COEFFICIENTS ANALYSES IN BASMATI RICE
}

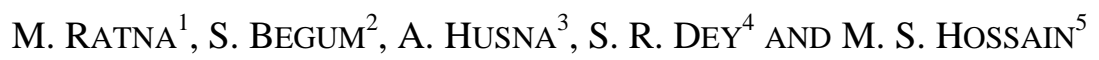

\begin{abstract}
Correlation and path coefficients analyses among fourteen morphological characters were studied in six advanced lines of Basmati rice and one commercial check namely BRRI Dhan 29. In general, genotypic correlation coefficients were higher than the corresponding phenotypic correlation coefficients suggesting that the environmental influence reduces the relationship between yield and yield contributing characters of rice. Correlation coefficient analysis showed significant positive correlation between plant height and panicle length at genotypic level. Number of filled spikelets/panicle showed significant positive correlation with yield at both genotypic and phenotypic levels but significant negative correlation was observed between plant height and yield. Number of effective tillers/plant had negative significant correlation with panicle length and with number of unfilled spikelets/panicle at genotypic level. Number of ineffective tillers/plant had significant negative correlation with 1000-seed weight at both genotypic and phenotypic levels. Path coefficient analysis revealed highest positive direct effect of number of filled spikelets/panicle on grain yield but plant height and number of unfilled spikelets/panicle had negative direct effect on grain.
\end{abstract}

Keywords: Correlation coefficient, genotypic level, path coefficient, rice, Oryza sativa.

\section{Introduction}

Rice (Oryza sativa L.) belongs to the family Gramineae. It is the staple food for at least $63 \%$ of planet inhabitants and contributes on an average $20 \%$ of apparent caloric intake of the world population and $30 \%$ of population in Asia (Calpe and Prakash, 2007). Over 90 percent of the world's rice is produced and consumed in the Asian Region by six countries (China, India, Indonesia, Bangladesh, Vietnam and Japan) comprising $80 \%$ of the world's production and consumption (Abdullah et al., 2006).

Cooked aromatic rice spread fragrance. Aromatic rice is a special group of rice, which is considered best in quality. Among the varieties of aromatic (fine) rice, Basmati rice are the most preferred in the international market and the trade is

\footnotetext{
${ }^{1}$ Spices Research Centre, Bangladesh Agricultural Research Institute (BARI), ${ }^{2}$ Scientific Officer, Plant Breeding Division, BARI, ${ }^{3}$ Department of Biotechnology, Patukhali Science and Technology University, ${ }^{4}$ Plant Breeding Division, BARI, ${ }^{5}$ Department of Genetics and Plant Breeding, Sher-e- Bangla Agricultural University, Bangladesh.
} 
exclusively shared between India and Pakistan. Basmati rices are characterized by superfine grain, pleasant aroma, soft texture and extreme grain elongation with least breadth-wise swelling on cooking (Singh et al., 2000). 'Bas' in Hindi language means "aroma" and 'Mati' means "full of" hence the word Basmati i.e. full of aroma. This rice is different from other rice mainly due to the aroma and elongation post cooking. It has its own unique aroma. This aroma is due to the presence of a chemical called 2-acetyl-1-pyrroline. That is about 12 times more than that of other types of rice. The cooked rice has a soft and flaky texture (Khus and Cruz, 2002). The price of Basmati rice is about 2-3 times higher than the coarse rice (Biswas et al., 1992). In spite of low yield potentiality, Basmati rice holds the unique position for its higher demand in the international market. The demand of basmati rice has been increasing in Bangladesh due to increase in per capita income and approaching self-sufficiency in rice production (BRRI, 2004). The climatic conditions of Bangladesh are also suitable to produce quality Basmati rice.

Economic product of rice is the grain yield, which exhibits complex genetics as it is influenced by various yield contributing characters and the environment. In general, increased number of fertile panicles is the single most important yield component associated with rice yield, number of spikelets/panicle; percent filled grains/panicle are also of secondary and tertiary importance (Jones and Synder, 1987). Another trait directly related to panicle is panicle density which chiefly affects the yield potential. These yield contributing components are interrelated with each other showing a complex chain of relationship and also highly influenced by the environmental conditions (Prasad et al., 2001). Breeding strategy in rice mainly depends upon the degree of associated characters as well as its magnitude and nature of variation (Zahid et al., 2006 and Prasad et al., 2001).Therefore, information about the yield contributing traits is of immense importance to the plant breeders for the development of improved varieties/ lines of rice with increased yield potential.

For rational approach towards the improvement of yield and its components, the association of characters with yield and among themselves and the extent of environmental influence on the characters are very much essential. Therefore, the knowledge of association of component characters with yield has great importance to plant breeders, as it helps in their selection with more precision and accuracy. The degree of relationship and association of these components with yield can be measured by correlation coefficients. But selection based on correlation without taking into consideration the interactions between the component characters may sometimes proven misleading (Codawat, 1980). Moreover, it does not give an exact position of the relative importance of direct and indirect effect of the various characters on yield. In path analysis, the correlation coefficient between two traits is separated into the components which 
measure the direct and indirect effects (Ahmadizadeh et al., 2011). Path coefficient analysis provides an exact picture of the relative importance of direct and indirect effects of each of the component character towards yield. With a view to having effective improvement of rice, its character associations as well as the nature and the extent of direct and indirect effects on yield were investigated.

\section{Materials and Method}

The study was conducted in the experimental field, Sher-e-Bangla Agricultural University, Dhaka, Bangladesh. The experimental field belongs to the Agroecological zone of "The Modhupur Tract", AEZ-28. Soil pH ranged from 6.0 6.6 and had organic matter of $0.84 \%$. Six different advanced lines of Basmati rice namely S1, S2, S5, 42(i), 42(ii), 44(i) collected from Department of Genetics and Plant Breeding from the same University were studied. BRRI Dhan-29 collected from Bangladesh Rice Research Institute was used as check. The experiment was laid out in Randomized Complete Block Design with three replications and with a plot size of $1.5 \mathrm{~m} \times 3.5 \mathrm{~m}$. Recommended cultural practices were followed through the growth period to raise the better crop. The fertilizers N, P, K, S and B in the form of urea, TSP, MOP, Gypsum and Borax, respectively were applied. The entire amount of TSP, MOP, Gypsum and Borax were applied during the final preparation of land. Urea was applied in two equal installments at tillering and panicle initiation stage. Rice seedlings were transplanted in the spacing of 30 $\mathrm{cm}$ X $25 \mathrm{~cm}$ on January, 2009. Data were recorded on plant height $(\mathrm{cm})$, days to $50 \%$ flowering, days to maturity, number of effective tillers/plant, number of ineffective tillers/plant, number of total tillers/plant, panicle length $(\mathrm{cm})$, number of filled spikelet/panicle, number of unfilled spikelets/panicle, number of total spikelets/panicle, weight of 1000-seeds (g), grain yield/plant (g), grain yield/plot $(\mathrm{kg})$. Estimation of phenotypic $\left(\mathrm{r}_{\mathrm{p}}\right)$ and genotypic $\left(\mathrm{r}_{\mathrm{g}}\right)$ correlation coefficients were estimated by the formula suggested by Miller et al., (1958). The path coefficients were calculated as per the formula given by Dewey and Lu (1959).

\section{Results and Discussion}

\section{Correlation studies}

Genotypic and phenotypic correlation coefficients between grain yield and other seven characters are presented in Table 1. In general, genotypic correlation coefficients were higher than their corresponding phenotypic correlation coefficients indicating that there is a strong inherent association between the characters studied. Plant height was correlated negatively and significantly with number of effective tillers/plant, number of ineffective tillers/plant, 1000-seed weight and grain yield at genotypic level. Amirthadevarathinam (1983) also found that grain yield was negatively correlated with plant height. But Bhadru et al., (2011) reported that plant height had a significant positive association with 
yield which was contradictory with this study. Plant height was significantly and positively correlated with panicle length at both genotypic and phenotypic level. Number of effective tillers/plant was correlated negatively and significantly with panicle length and with number of unfilled spikelets/panicle but positively and significantly correlated with grain yield at genotypic level. Eidi kohnaki et al., (2013), Kiani and Nematzadeh (2012), Akinwale et al. (2011), Basavaraja et al., (2011) and Shanthi et al., (2011) reported that productive tillers/plant showed significant positive correlation with grain yield.

Number of ineffective tillers/plant was correlated positively and significantly with 1000-seed weight but negatively and significantly correlated with panicle length at both genotypic and phenotypic levels. Panicle length was correlated negatively and significantly with 1000-seed weight and with grain yield at genotypic level. Similarly negative genotypic correlation of yield/plant was reported with panicle length by Saini and Gagneja (1975). Eidi kohnaki et al., (2013) and Kole et al., (2008) found a significant positive correlation between grain yield with panicle length. Number of filled spikelets/panicle was positively and significantly associated with grain yield at both genotypic and phenotypic levels. Eidi kohnaki et al., (2013), Haider et al., (2012), Kiani and Nematzadeh (2012), Seyoum et al., (2012), Akinwale et al. (2011), Akhtar et al., (2011) and Shanthi et al. (2011) reported the positive association of grain yield with filled grains/panicle.

\section{Path coefficient analysis}

Path coefficient analysis shown in table 2 revealed the results of direct and indirect effects of various grain components on grain yield ( $t / h a)$. It was observed that the highest positive direct effect of number of filled spikelets/panicle was on grain yield followed by 1000 -seed weight and days to $50 \%$ flowering. The direct positive effect of number of filled spikelets/ panicle on grain yield and positive significant genotypic correlation between these two traits indicates that direct selection through this trait would be much effective for the improvement of grain yield. High direct effect of filled spikelets/panicle on single plant yield was reported by Eidi kohnaki et al., (2013), Kiani and Nematzadeh (2012), Seyoum et al., (2012), Bagheri et al., (2011), Bhadru et al., (2011) and Chandra et al., (2009). All these reports support the present findings. Days to $50 \%$ flowering, number of effective tillers/plant and number of ineffective tillers/plant also had direct positive effect and positive genotypic correlation with grain yield. So, direct selection through this trait would also be effective for improvement of grain yield. Bhadru et al., (2011) and Chandra et al., (2009) reported positive direct effect of days to 50\% flowering and Eidi kohnaki et al., (2013) and Kiani and Nematzadeh (2012) found the positive direct effect and significant positive 


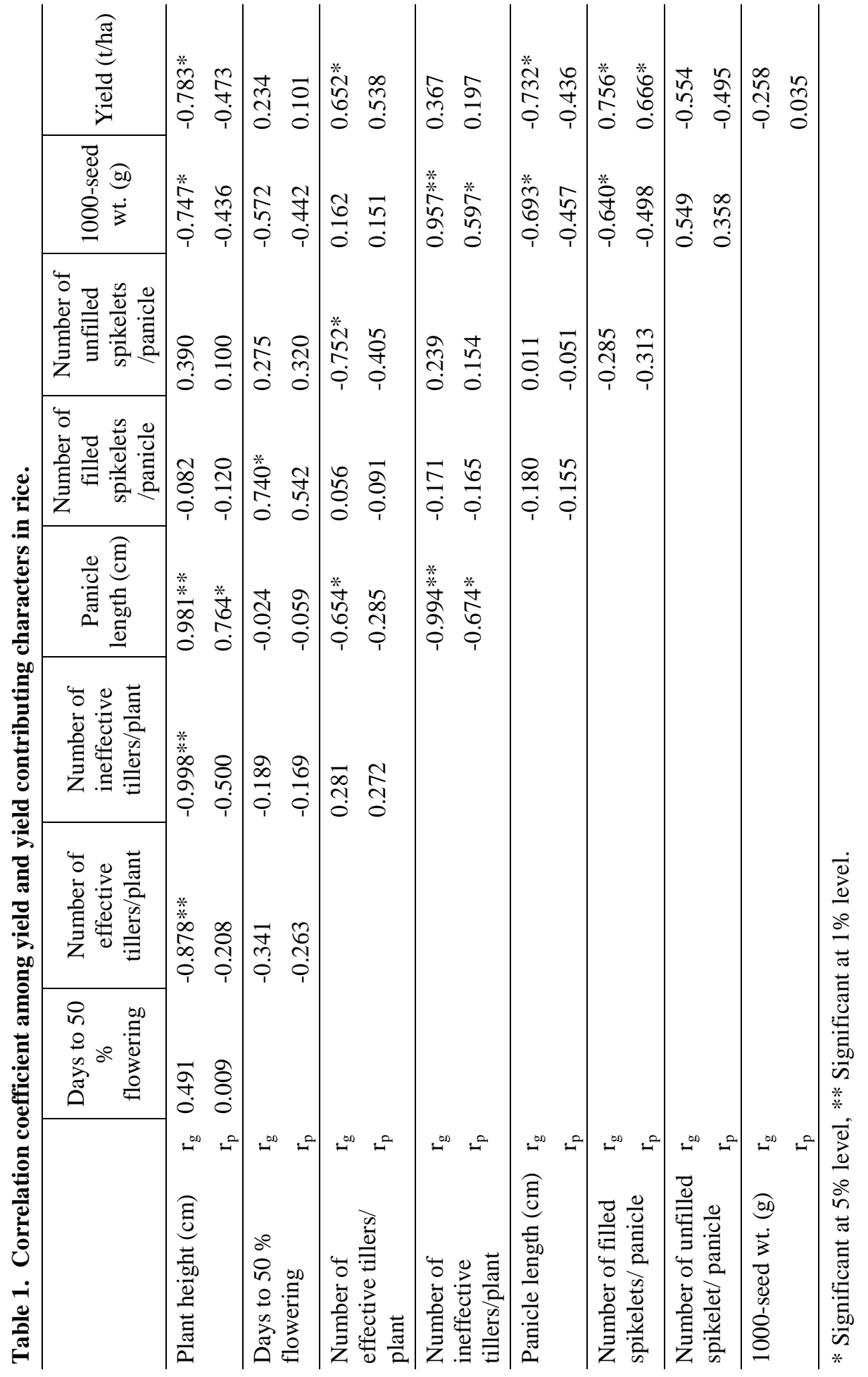




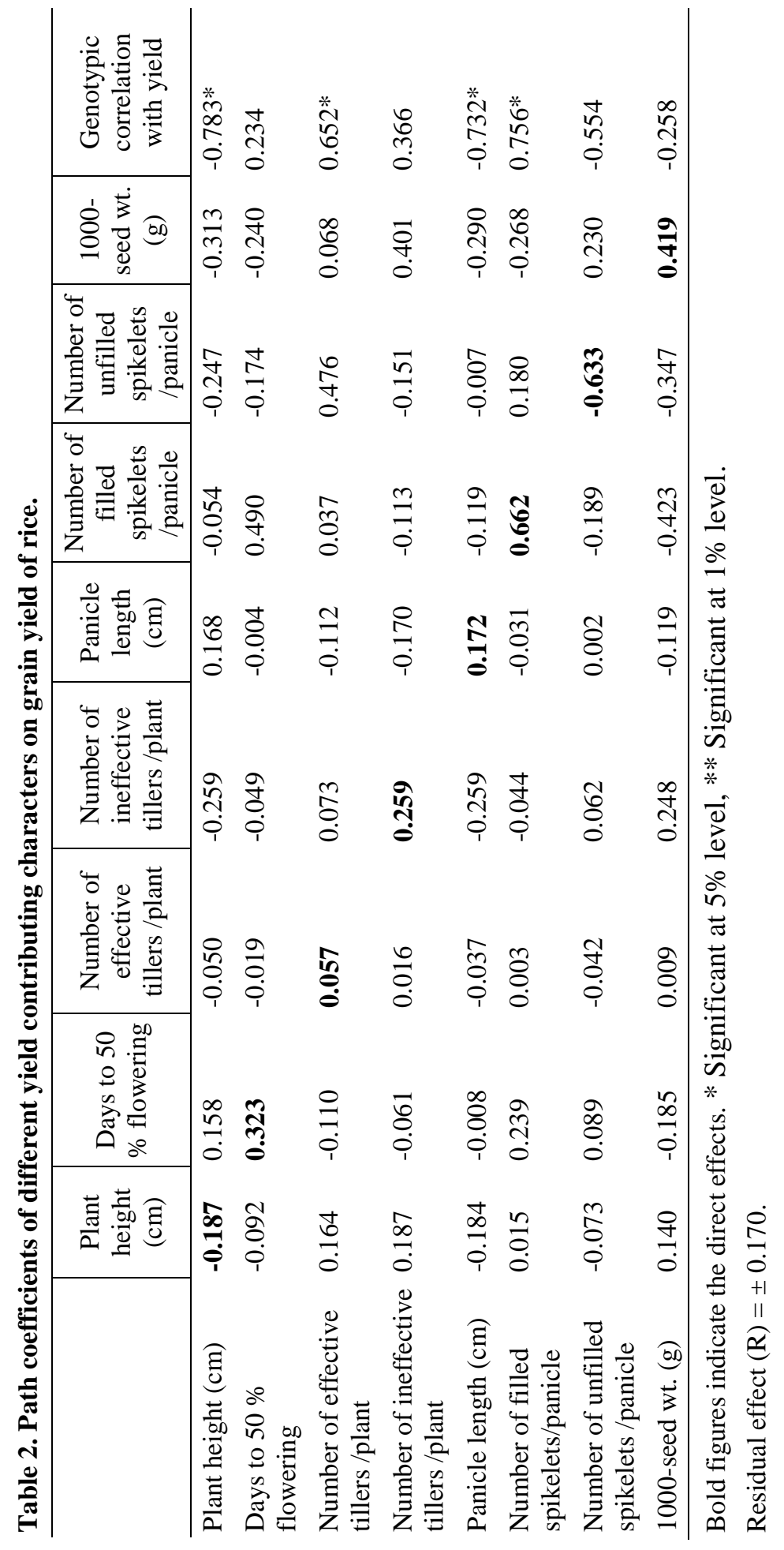


correlation coefficient between productive tillers/plant and grain yield/plant which also supported the present finding. Panicle length and 1000-seed weight had direct positive effect on grain yield but showed negative genotypic correlation with yield. Akhtar et al., (2011) found positive direct effect of 1000grain weight on yield. However, the results are in contrary with Eidi kohnaki et al., (2013) who reported that the1000-grains weight had negative direct effect on grain yield. Negative direct effect of plant height and number of unfilled spikelets/panicle on grain yield was observed. These two traits also showed negative genotypic correlation with grain yield. The direct effect and correlation coefficient of these two characters were negative, so the direct selection for these traits to improve the yield will not be desirable. Akhtar et al., (2011) also reported the negative direct effect of plant height on yield. But Eidi kohnaki et al., (2013), Bhadru et al., (2011) Nayak et al. (2001) and Shanthi and Singh (2001) reported a significant positive association of plant height with yield and also had a positive direct effect on yield both at the phenotypic and genotypic levels which is contradictory with the present study.

The estimated residual effect was 0.170 indicating that about $83 \%$ of the variability in grain yield was contributed by the characters studied in path analysis. This residual effect towards yield in the present study might be due to many reasons, such as other characters, which are not included in the investigation, environmental factor and sampling errors. Within the scope of path analysis carried out in the present study, it is therefore, suggested that number of filled spikelets/panicle and number of effective tillers/ plant, the main components of grain yield should be given high priority in the selection programme.

\section{References}

Abdullah, A. B., S. Ito and K. Adhana. 2006. Estimate of rice consumption in Asian countries and the world towards 2050. In Proceedings for Workshop and Conference on Rice in the World at Stake (Vol. 2), P. 28.

Ahmadizadeh, M., A. Nori, H. Shahbazi and S. Aharizad. 2011. Correlated response of morpho physiological traits of grain yield in durum wheat under normal irrigation and drought stress conditions in greenhouse. African Journal of Biotechnology 10(85): 19771-19779.

Akhtar, N., M. F. Nazir, A. Rabnawaz, T. Mahmood, M. E. Safdar, M. Asif and A.Rehman. 2011. Estimation of heritability, correlation and path coefficient analysis in fine grain rice (Oryza sativa L.) J. Anim. Plant Sci. 21(4): 660-664.

Akinwale, M. G., G. Gregorio, F. Nwilene, B. O. Akinyele, S. A. Ogunbayo and A. C. Odiyi. 2011. Heritability and correlation coefficient analysis for yield and its components in rice (Oryza sativa L.). Afr. J. Plant Sci. 5 (3): 207-212. 
Amirthadevarathinam, A., 1983. Genetic variability, correlation and path analysis of yield components in upland rice. Madras Agric. J. 70 (12): 781-785.

Bagheri, N., N. Babaeian-Jelodar, A. Pasha. 2011. Path coefficient analysis for yield and yield components in diverse rice (Oryza sativa L.) genotypes. Bih Biol. 5: 32-35.

Basavaraja, T., S. Gangaprasad, B. M. Dhusyantha Kumar, S. H. Hittlamani. 2011. Correlation and path analysis of yield and yield attributes in local rice cultivars (Oryza sativa L.). Electronic Journal of Plant Breeding 2(4):523 -526.

Bhadru, D., D. L. Reddy and M. S. Ramesha. 2011. Correlation and path coefficient analysis of yield and yield contributing traits in rice hybrids and their parental lines. Electronic Journal of Plant Breeding 2(1): 112-116.

Biswas, S. K., B. Banu, K. A. Kabir, F. Begum and N. H. Choudhury. 1992. Physicochemical properties of modern and local rice varieties of Bangladesh. Bang. Rice J. 3(1\&2): 181-188.

BRRI. 2004. Adhunik Dhaner Chash (Bengla), Pub. No. 5. Bangladesh Rice Res. Inst. Gazipur. Pp. 12-35.

Calpe, C. and A. Prakash. 2007. Sensitive and Special Products-a rice perspective. Commodity Market Review, FAO. Pp.49-71.

Chandra, B. S., T. D. Reddy, N. A. Ansari and S. S. Kumar. 2009. Correlation and path coefficient analysis for yield and yield components in rice (Oryza sativa L.). Agric. Sci. Digest 29 (1): 45-47.

Codawat, S. L. 1980. Notes on path coefficient analysis in foxtail millet [Setaria italica (L) Beauv.]. Madras Agril. J. 67: 690-692.

Dewey, D. R. and K. H. Lu. 1959. A correlation and path coefficient analalysis of components of crested wheat grass seed production. Agron. J. 51: $515-518$.

Eidi kohnaki, M., G. Kiani and G. Nematzadeh. 2013. Relationship between Morphological Traits in Rice Restorer Lines at F3 Generation using Multivariate Analysis. Int J Adv Biol Biom Res. 1(6):572-577.

Haider, Z., A. S. Khan and S. Zia. 2012. Correlation and Path Coefficient Analysis of Yield Components in Rice (Oryza sativa L.) Under Simulated Drought Stress Condition. Am-Euras. J. Agric. \& Environ. Sci. 12(1): 100-104.

Jones, D. B. and G. H. Synder. 1987. Seeding rate and row spacing effects on yield and yield components of ratoon rice. Agron. J. 79: 291-297.

Khus, G. S. and N.de.la Cruz. 2002. Developing Basmati rices with yield potential. In : R. Duffy, ed, Specialty rices of the World: Breeding, Production and marketing. Science Publisher, Enfield, USA. Pp.15-18.

Kiani, G. and G. Nematzadeh. 2012. Correlation and Path Coefficient Studies in F Populations of Rice. Not Sci Biol. 4(2):124-127.

Kole, P. C., N. R. Chakraborty and J. S. Bhat. 2008. Analysis of variability, correlation and path coefficient in induced mutants of aromatic non-basmati rice. Tropical agriculture research and extension. 11: 60-64. 
Miller, P. A., J. C. , Williams, H. F. Robinson and R. E.Comstock. 1958. Estimates of genotypic and environmental variances and co-variances in upland cotton and their implications in selections. Agron, J. 50: $126-131$.

Nayak, A. R., D. Chaudhury and J. N. Reddy. 2001. Correlation and path analysis in scented rice (Oryza sativa L.). Indian J. Agric. Res. 35: 186-189.

Prasad, B., A. K. Patwary and P. S. Biswas. 2001. Genetic variability and selection criteria in fine rice (Oryza sativa L.). Pakistan J. Biol. Sci. 4:1188-1190.

Saini, S. S. and M. R. Gagneja. 1975. Interrelationship between yield and some agronomic characters in short statured rice cultivars. Indian Journal of Genetics and Plant Breeding 35: 441-445.

Seyoum, M., S. Alamerew and K. Bantte. 2012. Genetic Variability, Heritability, Correlation Coefficient and Path Analysis for Yield and Yield Related Traits in Upland Rice (Oryza sativa L.). Journal of Plant Sciences 7(1): 13-22.

Shanthi, P. and J. Singh. 2001. Genetic divergence for yield and its components in induced mutants of Mahsuri rice (Oryza sativa L.). Res. Crops. 2: 390-392.

Shanthi, P., S. Jebaraj and S. Geetha. 2011. Correlation and path coefficient analysis of some sodic tolerant physiological traits and yield in rice (Oryza sativa L.). Indica $J$ Agric. Res. 45(3): 201-208.

Singh, R.K., G. S. Khush, U. S. Singh, A. K. Singh and S. Singh. 2000. Breeding Aromatic Rice for High Yield, Improved Aroma and Grain Quality, in Singh, Singh and Khush (eds), Aromatic Rices, Oxford \& IBH Publ., Pp.71-106.

Zahid, M. A., M. Akhtar, M. Sabir, Z. Manzoor and T. H. Awan. 2006. Correlation and path analysis studies of yield and economic traits in Basmati rice (Oryza sativa L.). Asian J. Plant Sci. 5: 643-645. 